\title{
Knowledge retention of basic life support in rural school adolescents: A comparison of two educational methods
}

\author{
Madhava Pai ${ }^{1}$, *Soundarya Mahalingam² ${ }^{2}$ Viveka Santhosh Reddy $\mathbf{C}^{1}$
}

Sri Lanka Journal of Child Health, 2022; 51(1): 119-125

DOI: http://dx.doi.org/10.4038/sljch.v51i1.10040

\begin{abstract}
Introduction: Basic life support (BLS) knowledge is essential and trained cardio-pulmonary resuscitation (CPR) by witnesses is associated with better survival. As our school curriculum does not cover essential BLS knowledge, this training was conducted to compare the knowledge retention on BLS training, using two educational modalities among high school students.
\end{abstract}

Objectives: To compare the knowledge retention on BLS training, using two educational modalities among high school students

Method: A non-randomised interventional control study was done where 458 rural high-school students were trained in BLS skills by two educational methods. Group I (229) underwent training by 'hands on' demonstrations and Group II (229) were trained by validated educational videos, both sessions lasting for 1 hour. The knowledge of BLS was assessed by a validated semi-structured 32 point questionnaire. Pre-test, post-test and 6 month knowledge retention test scores were compared and results analysed with Chi square test and paired t-test.

Results: Both groups had low baseline knowledge of BLS. Immediate retention of BLS training was significantly higher in group I (15.67/32 to 29/32) than group II $(14.67 / 32$ to $25 / 32)$ with $p<0.001$. The retention test showed statistically significant better scores in Group I (25.83/32) compared to Group II $(22.45 / 32)$ with $p<0.001$. However, both groups

\footnotetext{
${ }^{1}$ Resident, ${ }^{2}$ Associate Professor, Department of Paediatrics, Kasturba Medical College, Mangalore, Manipal Academy of Higher Education, Manipal, India

*Correspondence: soundarya.m@manipal.edu$$
\text { iD }
$$$$
\text { https://orcid.org/ 0000-0003-1417-0126 }
$$

(Received on 22 June 2021: Accepted after revision on 20 August 2021)

The authors declare that there are no conflicts of interest

Personal funding was used for the project.

Open Access Article published under the Creative

Commons Attribution CC-BY (c) (i) License
}

showed significant knowledge retention as compared to pre-training scores, with girls having better 6 month retention with a $\mathrm{p}$ value of 0.006 .

Conclusions: Training of rural school students helps to impart good knowledge of BLS with good retention with better retention following 'hands on' training as compared to educational videos. However, when compared to the existing level of training in rural schools, training by videos also helped to impart this essential knowledge.

(Key words: BLS, Basic life support training, Knowledge retention, Rural high school students, Adolescent training)

\section{Introduction}

To save lives after cardiac arrest, Basic Life Support (BLS) is considered a vital skill. It helps to maintain life until Cardio Pulmonary Resuscitation (CPR) is initiated. There have been improved outcomes with cardiac arrests occurring in public places as compared to private places like the home. This is probably due to the early and effective initiation of CPR by persons witnessing the event. Studies have shown that when CPR is initiated immediately after the cardiac arrest by others who have witnessed the event, the chances of survival are nearly 2 to 4 times higher ${ }^{1}$. The numbers of cardiac arrests that have been able to receive CPR at the site of the arrest by witnesses is around $60 \%$ in some countries and $20 \%$ in other countries ${ }^{2}$. In many homes, it is the children who are alone with their parents or grandparents; hence it is plausible that if BLS skill were to be a part of school curricula, the final outcomes of such CPR given by witnesses will be better. A review article in 2018 by Kuvaki B, et $a l^{3}$ has reported that children are very receptive and do not need extensive training to learn CPR. We conceived this study keeping in mind the resources available in India, aiming to provide training to high school students in BLS knowledge as an initial step. We used two different educational methods ('hands on' demonstrations and educational videos) to train the students and effectiveness of the training imparted was compared to identify which method can be recommended to be incorporated into the school curriculum. 


\section{Objectives}

To compare the knowledge retention on BLS training, using two educational modalities among high school students.

\section{Method}

Study design: Non-randomised interventional control study

Study setting: Rural Government schools in Dakshina Kannada district, Karnataka, India

Study duration: 2 years from November 2018 to October 2020

Study sample: Rural high school adolescents of class VIII and IX aged 13 - 14 years

Six rural government schools were selected after obtaining permission from the Block Educational Officer and the Principals of the respective schools.
Sample Size Calculation:

$$
\mathrm{n}=\mathrm{Z}_{\alpha}^{2} \mathrm{p} \mathrm{q}
$$

Sample size was 170 for one group with a confidence level of $95 \%$ and $90 \%$ power. However, 229 sample size per group was taken for the study as all the students in classes VIII (12 years and 10 months to 13 years and 10 months) and IX (13 years and 10 months to 14 years and 10 months) per school were included and no student was left out (Flow Chart).

\section{6 schools of Dakshina Kannada district were selected}

In each school all students of classes VIII and IX (age group 13-14 years) were included after parental consent

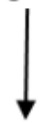

All schools were comparable in the student population with respect to income status of family, age of students and average performance in exams. In view of schools being rural government schools, all training and questionnaires were administered physically in a paper format, no online modality being used. Language used in test, during training sessions and in videos was Kannada which was the medium of instruction in the schools

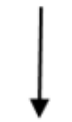

The schools have 4 sections each, which were grouped as 2 sections in Group I and 2 sections in Group 2. This form of convenient sampling was used in order to facilitate organisation of the training sessions

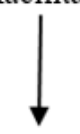

A total of 229 students were included in Group 1 and 229 in group 2 in this manner

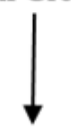

All students were given a validated semi-structured self-developed 32 point questionnaire pre-test at the start of the training which encompassed the basic details of BLS skills in an offline paper format. Each question was awarded 1 mark for the correct answer, making a net maximum score of 32 .

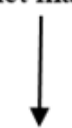

Both groups underwent their modality of training at the same time

\section{Flowchart of Method}

In group 1 students were trained by BLS trainers using mannequins and demonstrations for 1 hour by dividing them into smaller groups of 30 each. The students were allowed to ask questions and clarify doubts after the class. Due to logistic and time difficulties, the skills of the students could not be assessed individually but as a group

In group 2 the students were in their classrooms and were shown one validated BLS training video of 1 hour duration with animation included developed by 
the Department of Anaesthesia, Kasturba Medical College, Mangalore, India. These training sessions also had another BLS trainer available to clarify doubts after the class. Here too the class was for 1 hour and the videos had details about the BLS, need for BLS and the method of BLS in an unaided circumstance.

All the students were given a post-test immediately after their respective training sessions. The post-test was similar to the pre-test and the students were given 30 minutes to complete the questionnaire. After a period of 6 months, the schools were approached again and the retention test questionnaire was administered

Statistical analysis: The scores of the pre-test, immediate post-test and 6 month retention test were collated in both groups. The data obtained were assessed with the help of Statistical Package for the Social Sciences (SPSS) version 17.5. The statistical tests applied were the Chi square test for the count data and the paired t-test for the comparison between the pre-test and the post-test and pre-test and retention test.

Ethical issues: Approval for the study was obtained from the Institutional Ethics Committee of Kasturba Medical College, Mangalore, India (No. IEC/KMC/MLR/ID-18/375). Permission was obtained from the Block Educational Officer and the Principals of the respective schools. The study was also registered with the Clinical Trials RegistryIndia (CTRI). Clinical Trial Registration number is CTRI/2019/12/022440. Written informed consent was obtained from the parents and assent from the students.

\section{Results}

In our study we enrolled a total of 458 students (229 per group) from 6 rural schools. The results are described in 3 sections:

\section{Part A: Demography of the study population}

The number of students in Class VIII was 205 $(44.8 \%)$ and the number in Class IX was 253 $(55.2 \%)$. The number of male students in the study was 235 and the number of female students was 223 . The student population of both groups were comparable with respect to their socioeconomic status, literacy, parental occupation, medium of training and curriculum. Most other students had average and above average scholastic performance in the study sample as per their academic records and hence were comparable. However as we had segregated the students based upon their sections into the groups for the logistics of organising the training, it was noted that group 1 had 15 more girls than group II, which was unavoidable. Among the study population, none of the children had been trained in BLS and CPR as a part of their school curriculum. However, 7 students reported witnessing CPR attempted when a family member had cardiac arrest which was given by paramedical staff as a part of ambulance resuscitation.

\section{Part B: Knowledge of students in the BLS training - Descriptive analysis}

In this section, we analysed the knowledge of the students in the pre-test and post-test as well as in the retention test conducted 6 months after the training. When we compared the baseline pre-test scores of the questionnaire between group 1 and group II, they were comparable in their baseline knowledge of BLS/CPR as per their scores. However the difference between the groups was found statistically significant albeit by a smaller margin of $p=0.032$. This was explained by the fact that group 1 had more girls and in the analysis, girls performed better than the boys. Only $48.97 \%$ of the responses were correct in group I and $45.82 \%$ responses were correct in group II. This score improved to $90.80 \%$ correct responses in group 1 and $78.13 \%$ correct responses in group II in the immediate post-test. In the six months retention test $80.73 \%$ of the responses were correct in group 1 as compared to $70.16 \%$ in group II. (Table 1 )

Table 1: Scores between pre-test, post-test and retention test

\begin{tabular}{|c|c|c|c|c|c|c|c|c|c|}
\hline \multirow[t]{2}{*}{ Group } & \multicolumn{3}{|c|}{ Pre-test results } & \multicolumn{3}{|c|}{ Post-test results } & \multicolumn{3}{|c|}{ Six month retention test results } \\
\hline & $\begin{array}{l}\text { No. of total } \\
\text { responses }\end{array}$ & $\begin{array}{c}\text { No. of } \\
\text { correct } \\
\text { responses }\end{array}$ & $\begin{array}{c}\text { Out of } \\
32\end{array}$ & $\begin{array}{c}\text { No. of } \\
\text { total } \\
\text { responses }\end{array}$ & $\begin{array}{c}\text { No. of } \\
\text { correct } \\
\text { responses }\end{array}$ & Out of 32 & $\begin{array}{c}\text { No. of } \\
\text { total } \\
\text { responses }\end{array}$ & $\begin{array}{c}\text { No. of } \\
\text { correct } \\
\text { responses }\end{array}$ & $\begin{array}{c}\text { Out of } \\
32\end{array}$ \\
\hline $\begin{array}{l}\text { I. Hands on } \\
\text { training group }\end{array}$ & 7328 & 3589 & $\begin{array}{c}15.67 \\
(48.97 \%)\end{array}$ & 7328 & 6654 & $\begin{array}{c}29.05 \\
(90.80 \%)\end{array}$ & 7328 & 5916 & $\begin{array}{c}25.83 \\
(80.72 \%)\end{array}$ \\
\hline II. Video group & 7328 & 3358 & $\begin{array}{c}14.66 \\
(45.82 \%)\end{array}$ & 7328 & 5726 & $\begin{array}{c}25.0 \\
(78.13 \%)\end{array}$ & 7328 & 5142 & $\begin{array}{c}22.45 \\
(70.16 \%)\end{array}$ \\
\hline
\end{tabular}

Part C: Effectiveness of the educational tool used in retention of knowledge regarding $B L S$ skill

Here the knowledge acquired was compared between the pre-test, post-test and 6 month retention test and this was also compared between the 2 groups for the effectiveness of the educational modality used. The immediate recall scores in the post-test assess the effectiveness of the knowledge imparted during the training. In Group I, the average score in the pre-test was $15.67 / 32$ and this increased 
to $29.05 / 32$ in the immediate post-test conducted soon after the training. In Group II, the average score of $14.66 / 32$ initially, improved to $25 / 32$ after the training implying effective training given during the session in both groups. This improvement in the knowledge between group I and group II from the baseline knowledge, after the training, was found to be statistically significant with a $\mathrm{p}$ value $<0.001$. (Table 2). When the retention of knowledge was compared between the two groups at the end of six months, Group I scored 25.83/32 as compared to $22.45 / 32$ in group II. The better scores of Group I as compared to Group II in the six month retention test, was also found to be statistically significant with $p$ value $<0.001$ signifying that demonstrations through mannequins was a more effective tool in imparting BLS education as compared to educational videos. (Table 2)

Table 2: Comparison of mean knowledge between Group I and Group II

\begin{tabular}{|l|c|c|c|c|c|}
\hline \multicolumn{1}{|c|}{ Questionnaire } & Group & Mean & Standard deviation & t & p value \\
\hline Pre-test & Group 1 & 15.67 & 2.805 & 2.452 & 0.032 \\
\cline { 2 - 5 } & Group II & 14.66 & 2.843 & & $<0.002$ \\
\hline \multirow{2}{*}{$\begin{array}{l}\text { Immediate retention } \\
\text { /Post-test }\end{array}$} & Group 1 & 29.06 & 1.519 & & $<0.001$ \\
\cline { 2 - 5 } $\begin{array}{l}\text { 6 month retention } \\
\text { of knowledge }\end{array}$ & Group II & 25.00 & 3.295 & 10.337 & $<\mathbf{0 . 0 0 1}$ \\
\cline { 2 - 5 } & Group 1 & 25.83 & 3.066 & & \\
\hline
\end{tabular}

Upon comparing the knowledge retention at the end of three months to the baseline knowledge among all the students before the training (inclusive of both groups), the scores were $15.17 / 32$ in combined group at baseline as compared to $24.14 / 32$ during retention at the end of six months. This retention of
BLS knowledge was also found to be highly significant with $p$ values of $<0.001$, signifying the importance of training the students in BLS and their receptiveness irrespective of the educational tool used to impart the training (Table 3).

Table 3: Comparison of mean values of pre-test and retention in both groups together

\begin{tabular}{|l|c|c|c|c|c|c|}
\hline Questionnaire & Mean & $\begin{array}{c}\text { Standard } \\
\text { deviation }\end{array}$ & $\begin{array}{c}\text { Pre to post difference } \\
\text { (Mean) }\end{array}$ & SD & T value & P value \\
\hline Pre-test & 15.17 & 2.866 & 8.976 & 4.082 & 47.059 & $<\mathbf{0 . 0 0 1}$ \\
\hline Retention & 24.14 & 3.883 & & & & \\
\hline
\end{tabular}

When the comparison on knowledge was done between the male and female students, the baseline scores showed statistical significance with $p=0.021$, with girls faring better than the boys. However, despite this baseline difference, the scores in the immediate post-test and retention test when compared to the pre-tests showed statistically significant improvement in knowledge as explained further.

Table 4 shows the comparison of mean knowledge between genders. In the immediate post-test female students scored 27.46/32 when compared to
26.62/32 among the male students which had a $p$ value of 0.006 . The increase of mean knowledge score from pre-test to post-test in male students was 11.75 whereas in females it was 11.97 which was more than males but statistically not significant. Even in the six month retention test, female students score $24.59 / 32$ as compared to 23.53 among the male students which showed statistical significance with a $p$ value of 0.001 . Upon comparing knowledge from post-test to retention the decrease of mean knowledge was 3.09 in male students and 2.67 in female students. This decrease in knowledge was not found to be statistically significant.

Table 4: Comparison of mean knowledge between genders

\begin{tabular}{|c|c|c|c|c|c|}
\hline Questionnaire & Gender & Mean & Standard deviation & T value & p value \\
\hline \multirow[t]{2}{*}{ Pre-test } & $(235)$ & 14.87 & 2.867 & \multirow[t]{2}{*}{2.311} & \multirow[t]{2}{*}{0.021} \\
\hline & Female (223) & 15.48 & 2.838 & & \\
\hline \multirow[t]{2}{*}{ Post-test } & Male $\quad(235)$ & 26.62 & 3.737 & \multirow[t]{2}{*}{2.771} & \multirow[t]{2}{*}{0.006} \\
\hline & Female (223) & 27.46 & 2.628 & & \\
\hline \multirow[t]{2}{*}{ Retention } & Male $\quad(235)$ & 23.53 & 4.386 & \multirow[t]{2}{*}{3.531} & \multirow[t]{2}{*}{0.001} \\
\hline & Female (223) & 24.79 & 3.153 & & \\
\hline
\end{tabular}

\section{Discussion}

The present study was done with the aim of imparting knowledge of BLS to rural high school students. The study first assessed the baseline knowledge of the students as the current government school syllabus does not cover BLS. Then we taught the students about BLS using two educational methods in order to assess if there is a difference in the level of knowledge imparted by either method. We chose to compare 'hands on' BLS training with 
training using educational videos, the thought being that educational videos are a lot more cost effective than 'hands on' training, and should the study show good knowledge being imparted through videos, we could recommend this for initial inclusion in the school curriculum.

In our study, the knowledge of high school adolescents was assessed to be below baseline at the start of the study with the mean pre-training scores being 14.8/32. Similar poor baseline knowledge was found in other studies done by Alateeq $\mathrm{M}$, et $a l^{4}$ in 2018 in Riyadh, and Alhakhamy NA, et $a l^{5}$ in 2020 where they have also reported the need to train school students in CPR due to poor baseline knowledge.

In our study, the training was given using two educational modalities and their effectiveness was compared using a post-test done soon after the training as well as after a period of six months in order to plan recommendation for inclusion of that method in the school curriculum. For testing the knowledge we used a self-developed, pre-tested and piloted, validated 32-point questionnaire which covered all important aspects about the knowledge of BLS; 458 students were trained with 229 in each limb of the training. The training for the students was provided by one of the researchers, who is a trained BLS instructor, to ensure that the technique was correct and accurate as well as to ensure that the steps were explained with reasoning to the students who participated in the study. All the 229 students were personally demonstrated the 'hands on' training in small groups of 30 and their doubts were clarified, thus ensuring correct knowledge of BLS.

Similar studies were done by Breckwoldt $\mathrm{J}$, et $a l^{6}$ in 2007 and Lesnik D, et $a l^{7}$ in 2011 upon the training of school students in BLS, but in none of studies was the sample size large and none of the studies have compared 2 methods of training for their effectiveness in imparting knowledge. Similar concordant findings were seen in a study by Saquib SA et $a l^{8}$ in 2020 but this was done on university healthcare interns. In a similar study done in Pakistan in 2011 by Naqvi $\mathrm{S}$, et $a l^{9}$, among 30 students, the average score achieved after pre-test was $10.17 \pm 4.17$. Following the BLS training in the post-test, the average scores showed a significant increase to $18.10 \pm 3.782$. After 3 months the students were asked to give a re-test on the same topic and they were found out to have a mean score of $17.67 \pm 4.122$. In our study, the sample size was much larger and the students after training showed good improvement in both groups, with the mean scores improving in both groups from their baseline in both the post-test and 6 month retention test, which was statistically significant. The use of two different methods was unique to our study. Our study showed a statistically significant difference in the baseline scores of both groups with Group I performing better, there was also statistically significant better baseline knowledge among girls than boys. Hence as group I had 15 more girls as compared to group II and due to operational and logistical issues in organising the training sessions for the students in separate sections, this group scored marginally better than the other group. However, the scores of both groups showed statistically significant improvement in both the post-test and the retention test, showing that either method imparted knowledge well compared to baseline. Another study done in 2014 by Fernandes $\mathrm{JM}$ et $a l^{10}$ showed a similar improvement from the baseline knowledge levels after training, but here they had made comparison between students of public and private schools.

Another study done in Spain by Foncesca del Posco $\mathrm{F}$, et $\mathrm{al}^{11}$ in 2016 on 608 teenagers, used a song for the training in CPR and found that when the song was incorporated, the retention of knowledge was better. Here the students were randomized into 2 groups; one as the control $(n=35)$ and the other as the intervention group $(n=87)$. The control group was provided a two hour theoretical and a 'hands on' course while the intervention group had the basic course plus a music video which showed safety checks and technique of CPR. They also had a memory test 1 month and 8 months following the initial training. The results showed a drastic improvement from $19.5 \%$ students performing CPR to $99.2 \%$ post training. In our study similarly, we have used 'hands on' training with mannequins as demonstration and compared this with training using videos and we found that when training was done 'hands on' for the students, it required more effort at arranging the sessions, but the knowledge was better imparted to the students with better post-test scores as well as better scores at six month retention.

Another study was conducted by Meissner $\mathrm{T}$ et $a l^{12}$ in Germany in 2012 where they assessed the students' knowledge of CPR training. The students were asked to perform CPR with a basic pre-training after providing scenarios regarding the same. After 4 months the students were called without prior notice and were tested. They reported that the students showed improvement following practical training and that the BLS skills of the students almost matched the level when they were initially trained. This finding concurs with our study in the results as well as in the time of re-testing for knowledge which occurred at a similar time interval of 6 months and showed good retention in both studies. 
In a study done in Manipal by Stemi $\mathrm{S}$, et $a l^{13}$ in 2017, 16 students were trained in administering CPR and their knowledge was tested by conducting a pretest, post-test and a retention test after 1 week. The mean scores substantially increased from $2.6 \pm 1.9$ in the pre-test to $12.44 \pm 0.89$ in post assessment and $12 \pm 1.05$ in the retention test. The students also showed more confidence in providing CPR after the basic training. This study reported a nearly same score at retention as in the immediate post-test which was probably because of the retention test being conducted just 1 week after the training session. In our study we conducted the retention test after six months and hence we report a marginal dip in the knowledge recall and this dip was not significant. The scores found in the post-test after six months were still higher than the pre-test scores in our study and this was statistically significant.

In the present study, differences between female and male students in their retention of knowledge was found to be statistically significant. However, in the study by Parnell M, et al ${ }^{14}$ in 2006 , they did not find any such gender differences. No other study had any such gender differences nor was any such correlation studied. But in our schools we have found that in the school (15 year) outgoing examinations, girls always outperform boys and hence that's how in our study too girls performed better than the boys.

With our study results, we recommend training of high school students in BLS to improve their baseline knowledge in BLS. This knowledge has best retention when imparted as 'hands on' training by a trained instructor rather than educational videos. However, both modalities of training students in BLS do improve their knowledge in BLS skills from the pre-existing level which is the need of the hour in India, a country with a large population in rural areas where the settings are resource limited such knowledge can form a foundation for further inclusion of such vital training in the school curriculum.

A limitation that we faced during the study was that we trained the students using two methods and could test only their recall knowledge, due to logistical difficulties in training and testing the skills in BLS in 458 students and hence only knowledge could be tested individually. Our study showed a statistically significant difference in the baseline knowledge of the groups, probably because of more girls in the Group I as compared to Group II and girls outperformed boys in the baseline scores. Ideally equal proportion of boys and girls should have been allocated into each group which we could not do due to operational difficulties of segregating students in school. Hence this is a limitation of our study.

\section{Conclusions}

Training of rural school students helps to impart good knowledge of BLS with good retention with better retention following 'hands on' training as compared to educational videos. However, when compared to the existing level of training in rural schools, training by videos also helped to impart this essential knowledge.

\section{Acknowledgements}

We thank all the parents and children who participated in the study. We also acknowledge all the help received in organisation of the training from the school authorities.

\section{References}

1. Wissenberg $\mathrm{M}$, Lippert FK, Folke F, Weeke P, Hansen CM, Christensen EF, et al. Association of national initiatives to improve cardiac arrest management with rates of bystander intervention and patient survival after out-of-hospital cardiac arrest. JAMA 2013; 310: 1377-84. https://doi.org/10.1001/jama.2013.278483

2. Gräsner JT, Bossaert L. Epidemiology and management of cardiac arrest: What registries are revealing. Best Practice and Research Clinical Anaesthesiology 2013; 27: 293-306.

https://doi.org/10.1016/j.bpa.2013.07.008

3. Kuvaki B, Özbilgin Ş. School children save lives. Turkish Journal of Anaesthesiology and Reanimation 2018; 46(3): 170-5. https://doi.org/10.5152/TJAR.2018.25986 PMID: 30140511; PMCID: PMC6097851.

4. Alateeq M, Al Harbi N, Afifi A, Tourkmani A, Alharbi T, Albattal S. Awareness of basic life support and cardiopulmonary resuscitation among female secondary school students in government schools in Riyadh city, KSA. Journal of Family Medicine and Primary Care 2018; 7(6): 1493.

https://doi.org/10.4103/jfmpc.jfmpc_21_1 8

5. Alhakamy NA, Zamzami AM, Bukhari FA, Bukhari FA, Almash OA, Madkhali MA, et al. Knowledge and attitude about basic life support and emergency medical services among pharmacy students at King Abdulaziz University, Jeddah, Saudi Arabia. Saudi Journal of Emergency Medicine 2020; 1(2):70-4. 
https://doi.org/10.24911/SJEMed/7215820 51345

6. Breckwoldt J, Beetz D, Schnitzer L, Waskow C, Arntz HR, Weimann J. Medical students teaching basic life support to school children as a required element of medical education: a randomised controlled study comparing three different approaches to fifth year medical training in emergency medicine. Resuscitation 2007; 74(1): 158-65. https://doi.org/10.1016/j.resuscitation. 200 6.11 .017

7. Lešnik D, Lešnik B, Golub J, Križmarić M, Mally S̆, Grmec Š. Impact of additional module training on the level of basic life support knowledge of first year students at the University of Maribor. International Journal of Emergency Medicine 2011; 4(1): 16 .

https://doi.org/10.1186/1865-1380-4-16

8. Saquib SA, Al-Harthi HM, Khoshhal AA, Shaher AA, Al-Shammari AB, Khan A, et al. Knowledge and attitude about basic life support and emergency medical services amongst healthcare interns in university hospitals: a cross-sectional study. Emergency Medicine International 2019; 2019: 9342892

https://doi.org/10.1155/2019/9342892

9. Naqvi S, Siddiqi R, Hussain S. School children training for basic life support. Journal of College of Physicians and Surgeons Pakistan 2011; 21(10): 611-5.

10. Fernandes JM, Leite AL, Auto Bde S, Lima JE, Rivera IR, Mendonça MA. Teaching basic life support to students of public and private high schools. Arq Bras Cardiol. 2014; 102(6): 593-601.

https://doi.org/10.5935/abc.20140071

PMID: 25004421; PMCID: PMC4079024.

11. Fonseca del Pozo F, Valle Alonso J, Canales Velis N, Andrade Barahona M, Siggers A, Lopera E. Basic life support knowledge of secondary school students in cardiopulmonary resuscitation training using a song. International Journal of Medical Education 2016; 7: 237-41. https://doi.org/10.5116/ijme.5780.a207

12. Meissner T, Kloppe C, Hanefeld C. Basic life support skills of high school students before and after cardiopulmonary resuscitation training: a longitudinal investigation. Scandinavian Journal of Trauma, Resuscitation and Emergency Medicine 2012; 20(1):31.

https://doi.org/10.1186/1757-7241-20-31

13. Stemi S, Babu A, Unnikrishnan R. Basic life support skills for high school students pre and post-cardiopulmonary resuscitation training- An interventional study. Indian Journal of Respiratory Care 2017; 6(1): 786-90.

14. Parnell M, Pearson J, Galletly D, Larsen P. Knowledge of and attitudes towards resuscitation in New Zealand high-school students. Emergency Medicine Journal 2006; 23(12): 899-902 https://doi.org/10.1136/emj.2006.041160 